\title{
ANALISIS KEBIJAKAN DAMPAK PENYESUAIAN HARGA BBM BERSUBSIDI UNTUK NELAYAN
}

\section{Analysis of Subsidized Fuel Price Adjustment Policy Impact For Fishers}

\author{
"Subhechanis Saptanto, Achmad Zamroni, \\ Andrian Ramadhan dan Rizky Aprilian Wijaya \\ Pusat Penelitian Sosial Ekonomi Kelautan dan Perikanan \\ Gedung Balitbang KP I Lt. 4 \\ Jalan Pasir Putih Nomor 1 Ancol Timur, Jakarta Utara, Indonesia \\ Telp: (021) 64711583 Fax: 64700924 \\ Diterima tanggal: 24 Agustus 2016 Diterima setelah perbaikan: 25 September 2016 \\ Disetujui terbit: 3 Desember 2016 \\ *email: anis_saptanto@yahoo.com
}

\begin{abstract}
ABSTRAK
Fluktuasi harga BBM yang disebabkan oleh adanya kebijakan penyesuaian harga BBM memberikan pengaruh pada berbagai sektor khususnya sektor perikanan tangkap. Tujuan dari penelitian ini mengkaji pengaruh penyesuaian harga BBM terhadap biaya operasional usaha perikanan tangkap laut; dan mengkaji dampak penyesuian harga BBM terhadap tingkat keuntungan usaha perikanan tangkap laut. Waktu penelitian dilaksanakan selama 30 hari kerja yang dilakukan pada bulan JanuariFebruari 2015. Lokasi penelitian dilakukan di Pelabuhan Perikanan Pantai (PPP) Muncar, Pelabuhan Perikanan Nusantara (PPN) Brondong Kabupaten Lamongan, PPN Pekalongan di Kota Pekalongan dan PPN Palabuhan Ratu di Kabupaten Sukabumi, dengan pertimbangan bahwa di lokasi tersebut terdapat armada kapal berdasarkan ukuran kapal. Data yang digunakan dalam penelitian ini adalah data primer dan sekunder. Data primer diperoleh dari responden/sampel penelitian yang ditentukan secara purposif (purposive sampling) mencakup: nelayan pada berbagai ukuran kapal. data-data sekunder diperoleh dari laporan penelitian, laporan kajian, dan data-data pada berbagai instansi terkait. Data ditabulasi dan dianalisis secara deskriptif dan disajikan dalam bentuk tabel-tabel. Hasil penelitian menunjukkan bahwa penyesuaian harga BBM memiliki pengaruh yang sangat besar terhadap biaya operasional dan keuntungan usaha. Pada seluruh ukuran kapal peningkatan harga BBM akan secara otomatis meningkatkan biaya operasional usaha dan menurunkan keuntungan usaha. Perubahan harga BBM khususnya solar yang terjadi pada akhir tahun 2014 hingga Januari 2015 memberikan dampak positif dan negatif terhadap pelaku usaha, khususnya nelayan; penurunan harga BBM berpotensi menaikkan tingkat keuntungan yang diterima, sebaliknya peningkatan BBM berpotensi menurunkan tingkat keuntungan usaha. Perlu adanya bantuan permodalan dan pendampingan untuk mendorong pelaku usaha berpindah dari kapal 50-100 GT ke kapal berukuran 20-30 GT atau ke kapal berukuran di atas 100 GT. Hal ini didasarkan pada hasil kajian dimana kelompok ukuran kapal 50-100 GT yang paling sensitif terkena dampak akibat perubahan harga solar. Setiap kenaikan harga BBM solar sebesar $1 \%$ akan menurunkan keuntungan usaha sebesar 0,7\%. Sementara ukuran kapal 20-30 GT dan di atas 100 GT mengalami penurunan sebesar $0,2 \%$ dan $0,5 \%$.
\end{abstract}

Kata Kunci: BBM, nelayan, analisis usaha, subsidi

\section{ABSTRACT}

Fluctuations in fuel prices caused by the fuel price adjustment policy influence on various sectors particularly the fisheries sector. The purpose of this study was to assess the effect of fuel price adjustments against operating expenses marine capture fishery business; and assess the impact of fuel price adjustments to the level of profitability of marine capture fisheries. The research was carried out for 30 days of work, done in January-February 2015. The research location is at the Fishery Port Beach (PPP) Muncar, Nusantara Fishery Port (VAT) Brondong Lamongan, PPN Pekalongan in Pekalongan and VAT Palabuhan Ratu in Sukabumi, considering that in that location there is a fleet of ships based on ship size. The data used in this study are primary and secondary data. Primary data obtained from respondents / sample were determined purposively (purposive sampling) include: fisherman on vessels 
of various sizes. secondary data obtained from research reports, assessment reports, and data on the various relevant agencies. Techniques used for primary data collection is interview the selected respondents, with the scope of information covering investment costs, variable costs (variable) per trip, the fixed cost (fixed) per year, business receipts per trip, business operational information. Data tabulated and analyzed descriptively and presented in a tabular format. The results showed that the adjustment of fuel prices has a profound influence on operating costs and profits. On the whole size of ships increase in fuel prices will automatically increase business operational costs and lowering profits. Changes in fuel prices, especially diesel which occurred in late 2014 to January 2015 giving positive and negative impacts to businesses, especially fishermen fishing; reductions in fuel prices could raise the level of benefits received, otherwise the increase in fuel potentially lower level of profits. The need for capital assistance and mentoring to encourage businesses to move from ship to ship size 50-100 20-30 GT GT or sized vessels above $100 \mathrm{GT}$. It is based on the results of the study in which groups of vessel sizes 50-100 GT are most sensitive affected by changes in the price of diesel. Any increase in the price of diesel fuel by $1 \%$ would reduce the business profits of $0.7 \%$. While the size of $20-30$ ships over 100 GT and GT decreased $0.2 \%$ and $0.5 \%$.

Keywords: fuel, fishers, business analysis, subsidies

\section{PENDAHULUAN}

Bahan Bakar Minyak (BBM) merupakan input produksi vital bagi kegiatan usaha produksi ikan di sektor kelautan dan perikanan, baik pada usaha-usaha perikanan tangkap, budidaya maupun pengolahan. Pada usaha perikanan tangkap, pengeluaran untuk pembelian BBM mencapai $50-70 \%$ dari total biaya operasional melaut. Beberapa hal yang mempengaruhi besar kecilnya pengeluaran BBM diantaranya adalah besaran ukuran kapal, jenis peralatan tangkap yang digunakan, jangka waktu melaut, banyaknya trip penangkapan dalam suatu periode, jarak ke lokasi tangkapan, dan lain sebagainya. Kondisi saat ini, usaha nelayan untuk melakukan penangkapan ikan semakin bertambah besar karena sumberdaya perikanan semakin sulit ditemukan. Nelayan harus menambah hari dan jarak melaut untuk menangkap ikan yang ketersediaannya semakin langka dan berkurang (Kinseng, 2007). Perkembangan terkini, nelayan dihadapkan pada ketidakpastian harga BBM bersubsidi dan sulitnya memperoleh BBM bersubsidi. Kondisi ini menyebabkan ketidakpastian usaha perikanan tangkap.

Menurut Todaro and Smith (2009), subsidi adalah bentuk bantuan keuangan yang dibayarkan kepada suatu bisnis atau sektor ekonomi. Sedangkan menurut Spencer et al. dalam Handoko dan Patriadi (2005), subsidi merupakan pembayaran yang dilakukan pemerintah kepada perusahaan atau rumah tangga untuk mencapai tujuan tertentu yang membuat mereka dapat memproduksi atau mengkonsumsi suatu produk dalam kuantitas yang lebih besar atau pada harga yang lebih murah. Secara ekonomi, tujuan subsidi adalah mengurangi harga atau menambah keluaran (output). Sedangkan menurut Sukirno (2005), subsidi pada dasarnya merupakan pemberian pemerintah kepada produsen untuk mengurangi biaya produksi yang ditanggung oleh produsen.

Nugroho (2005) mendefinisikan subsidi yang berkaitan dengan subsidi BBM yaitu pembayaran yang dilakukan oleh Pemerintah Indonesia kepada Pertamina, sebagai pemegang monopoli pendistribusian BBM di Indonesia, dalam situasi dimana pendapatan yang diperoleh PT Pertamina (persero) dari tugas menyediakan BBM di pasar domestik lebih rendah dibandingkan biaya yang dikeluarkan untuk menyediakan dan mendistribusikan BBM. Subsidi BBM menjadi salah satu instrumen untuk memeratakan penggunaan energi di masyarakat, terutama masyarakat berpenghasilan rendah. Kebijakan subsidi diberlakukan pada saat harga suatu produk energi dinilai tidak sebanding dengan daya beli masyarakat khususnya masyarakat yang berpenghasilan rendah (Yusgiantoro, 2000).

Pada awal pemerintahannya, Presiden Indonesia menaikkan harga BBM bersubsidi. Kenaikan tersebut dipicu oleh tingginya impor BBM yang dilakukan oleh Indonesia ditambah adanya kenaikan harga minyak dunia. Kondisi ini menyebabkan keuangan negara terbebani untuk BBM bersubsidi. Pemerintah mengumumkan kenaikan harga BBM pada tanggal 18 November 2014 dimana BBM jenis solar naik sekitar 36\% dari Rp. 5.500 per liter menjadi Rp. 7.500 per liter dan BBM jenis bensin premium naik sebesar 
$31 \%$ dari Rp. 6.500 per liter menjadi Rp. 8.500 per liter. Pada awal tahun 2015, terjadi fluktuasi harga minyak dunia yang cenderung turun. Kondisi ini menyebabkan pemerintah mengambil kebijakan untuk menurunkan kembali harga BBM bersubdisi. Bahkan dalam Bulan Januari tahun 2015, terjadi penurunan harga sebanyak 2 kali (Tabel 1).

Fenomena penyesuaian harga BBM bersubsidi di masa-masa mendatang kemungkinan besar akan terjadi mengingat pemerintah mewacanakan menetapkan floating price untuk BBM. Bagi pelaku usaha perikanan tangkap, ketidakpastian harga BBM menyebabkan ketidakpastian usaha penangkapan juga. Pada saat harga BBM mengalami kenaikan, sebagian besar pelaku usaha merasa terhambat atau bahkan tidak dapat melakukan aktivitas penangkapan. Sisi positifnya, tekanan terhadap sumber daya perikanan berkurang karena effort nelayan juga berkurang sehingga stok sumber daya dapat meningkat. Sebaliknya, apabila harga BBM menurun, pelaku usaha mendapatkan angin segar untuk dapat kembali melakukan aktivitas usahanya, namun sumber daya perikanan kembali tertekan.

Selain permasalahan penyesuaian harga BBM bersubsidi, berkembang pula wacana terkait dengan siapa yang berhak memperoleh BBM bersubsidi pada pelaku usaha perikanan. Mengacu kepada Peraturan Presiden Nomor 191 Tahun 2014", terdapat batasan bahwa kapal berukuran lebih dari 30 GT tidak memperoleh jatah BBM bersubsidi, artinya pelaku usaha dengan ukuran kapal lebih besar dari 30 GT harus membeli BBM dengan harga keekonomian. Alasan utama mengapa kapal berukuran lebih dari 30 GT tidak mendapatkan jatah subsidi BBM diantaranya adalah pertama, BBM subsidi mengalami kebocoran akibat penjualan BBM subsidi dengan harga non subsidi di tengah laut (Alamsyah, 2014). Kedua, nelayan kecil (berukuran kurang dari 30 GT) mengkonsumsi sedikit dari jatah subsidi yang disediakan yang mana penggunaan BBM bersubsidi justru paling besar dinikmati oleh kapal bertonase di atas $30 \mathrm{GT}$, yakni hampir 60-70 persen dari total alokasi BBM bersubsidi (Anonim, 2014). Ketiga, dengan pembatasan subsidi BBM kepada kapal berukuran lebih dari 30 GT, maka pemerintah melalui Kementerian KElautan dan Perikanan (KKP) memiliki dana sebesar Rp. 11 triliun untuk dialihkan mengganti kebutuhan nelayan (Maharani, 2014).

Pembatasan subsidi BBM hanya kepada kapal berukuran < 30 GT juga mengakibatkan beberapa hal diantaranya pertama, akan terjadi gejolak sosial akibat dari menganggurnya anak buah kapal (ABK) karena operasi penangkapan ikan berhenti (Saleh, 2013). Kedua, secara langsung, apabila kebijakan tersebut diterapkan akan berdampak negatif terhadap upaya pencapai target produksi ikan dari usaha penangkapan ikan; dan secara langsung juga akan berpengaruh terhadap tingkat pendapatan nelayan yang pada gilirannya berakibat pada tingkat kesejahteraan kelompok masyarakat nelayan tersebut.

Berdasarkan pemaparan tersebut, maka analisis kebijakan penyesuaian harga BBM bersubsidi untuk nelayan relevan dilakukan. Pertanyaan penelitian yang akan dijawab diantaranya adalah bagaimana pengaruh dari kenaikan atau penurunan harga BBM bersubsidi terhadap biaya operasional dan keuntungan

Tabel 1. Perubahan Harga BBM Bersubsidi Periode Juni 2014 - Januari 2015.

Table 1. Changes in Subsidized Fuel Prices The Period June 2014 - January 2015.

\begin{tabular}{llc}
\hline \multicolumn{1}{c}{ Tanggal/ Date } & \multicolumn{1}{c}{$\begin{array}{c}\text { Harga BBM Solar bersubsidi/ } \\
\text { Fuels Subsidizes Price }\end{array}$} & Perubahan/Change (\%) \\
\hline 22 Juni 2014 & Rp. 5.500 & $(+) 36 \%$ \\
18 November 2014 & Rp. 7.500 & $(-) 15 \%$ \\
19 Januari 2015 & $\begin{array}{l}\text { Rp. } 6.400 \text { (seluruh Indonesia, kecuali Bali \& Madura/ } \\
\end{array}$ & All of Indonesia except Bali and Madura) \\
& Rp. 6.720 (Bali dan Madura) & \\
\hline
\end{tabular}

Sumber: Data Primer Diolah/Source: Primary Data Processed, 2015

\footnotetext{
${ }^{1}$ PERATURAN PRESIDEN NO 191 TAHUN 2014 tentang penyediaan, pendistribusian dan harga jual eceran bahan bakar minyak. "Nelayan yang menggunakan kapal ikan Indonesia dengan ukuran maksimum 30 (tiga puluh) GT yang terdaftar di Kementerian Kelautan dan Perikanan dan Perikanan SKPD Provinsi/Kabupaten/Kota yang membidangi perikanan dengan verifikasi dan surat rekomendasi dari pelabuhan perikanan atau kepala SKPD Provinsi/Kabupaten/Kota yang membidangi perikanan sesuai dengan kewenangannya masing - masing.
} 
usaha perikanan tangkap?. Berapa besaran harga BBM subsidi yang ideal yang dapat diterima oleh nelayan? Oleh karena itu, upaya perumusan kebijakan yang bersifat antisipatif maupun responsif terhadap kebijakan penyesuaian harga BBM maupun subsidi BBM pada sektor perikanan perlu dilakukan. Upaya perumusan kebijakan juga bermaksud untuk memberikan saran dan masukan kepada pemangku kebijakan khususnya Menteri Kelautan dan Perikanan dalam bentuk langkahlangkah apa yang perlu dilakukan sehingga kegatan usaha perikanan tangkap tetap lestari sekaligus kesejahteraan masyarakat pelaku usaha perikanan tangkap dapat ditingkatkan. Tujuan penelitian ini adalah untuk: (1) mengkaji pengaruh penyesuaian harga BBM terhadap biaya operasional usaha perikanan tangkap laut, dan; (2) mengkaji dampak penyesuaian harga BBM terhadap tingkat keuntungan usaha perikanan tangkap laut.

\section{METODOLOGI}

\section{Kerangka Pemikiran}

Kegiatan usaha penangkapan merupakan kegiatan pemanfaatan sumberdaya ikan di laut oleh pelaku utama yaitu nelayan. Usaha perikanan tangkap merupakan kegiatan usaha perikanan yang dalam kegiatan operasi penangkapannya menggunakan Bahan Bakar Minyak (BBM) sebagai penggerak kapal motor. Dalam hal ini, BBM menjadi salah satu komponen utama dengan biaya yang dikeluarkan untuk BBM ini memiliki persentase yang cukup besar dari keseluruhan biaya setiap trip nya. Kerangka pemikiran analisis kebijakan penyesuaian harga BBM bersubsidi untuk nelayan ditampilkan pada Gambar 1.

\section{Waktu dan Lokasi Penelitian}

Kegiatan ini dilaksanakan selama 30 hari kerja yang dilakukan pada bulan Januari - Februari 2015. Lokasi penelitian dilakukan di Pelabuhan Perikanan Pantai (PPP) Muncar, Pelabuhan Perikanan Nusantara (PPN) Brondong Kabupaten Lamongan, PPN Pekalongan di Kota Pekalongan dan PPN Palabuhan Ratu di Kabupaten Sukabumi, dengan pertimbangan bahwa di lokasi tersebut terdapat armada kapal berdasarkan ukuran kapal.

\section{Jenis, Sumber dan Metode Pengumpulan Data}

Untuk memperoleh data dan informasi secara komprehensif dan akurat, analisis ini didukung oleh data-data primer dan sekunder. Data primer diperoleh dari responden/sampel penelitian yang ditentukan secara purposif (purposive sampling) mencakup: nelayan pada berbagai ukuran kapal (< 5 GT, 5 - 10 GT, 10 - 20 GT, 30 - 50 GT, 50 - 100 GT, 100 - 200 GT dan > 200 GT). Pada tiap ukuran kapal tersebut dipilih jenis alat tangkap yang dominan di masing-masing lokasi penelitian. Sementara itu, data-data sekunder diperoleh dari laporan penelitian, laporan kajian, dan data-data pada berbagai instansi terkait.

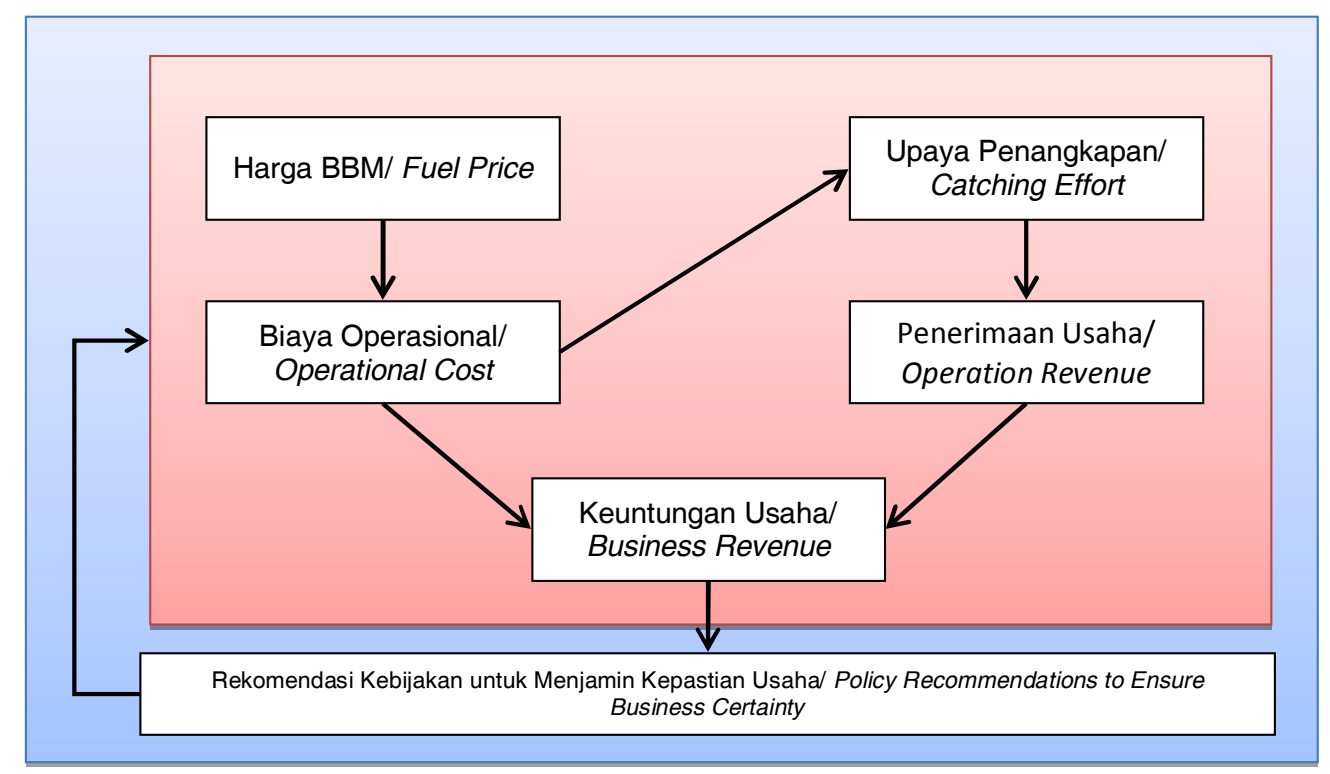

Gambar 1. Kerangka Pemikiran Analisis Kebijakan Penyesuaian Harga BBM Bersubsidi Untuk Nelayan Tahun 2015.

Figure 1. Framework Analysis of Subsidized Fuel Price Adjustment Policy for the Fisherman 2015. 
Teknik yang dipergunakan untuk pengumpulan data primer adalah teknik wawancara terhadap responden terpilih, dengan cakupan informasi meliputi biaya investasi, biaya tidak tetap (variable) per trip, biaya tetap (fixed) per tahun, penerimaan usaha per trip, informasi operasional usaha. Jumlah responden yang diambil totalnya ada 44 responden.

\section{Metode Analisis Data}

Data yang terkumpul melalui metode survei dan studi pustaka ditabulasi dan dianalisis secara deskriptif dan disajikan dalam bentuk tabeltabel. Pembahasan dalam kajian ini difokuskan pada dinamika usaha perikanan tangkap menurut berbagai ukuran kapal pada saat sebelum dan sesudah kenaikan harga BBM yang terjadi bulan November tahun 2014 dan bulan Januari 2015. Analisis yang dilakukan adalah analisis statistik deskriptif dan analisis usaha.

Perhitungan analisis usaha menggunakan rumus sebagai berikut (Harianto, 2003):

$$
\text { Л }=\text { TR }-\mathrm{TC}
$$

Total Cost (TC) dihitung melalui rumus :

$$
\mathrm{TC}=\mathrm{FC}+\mathrm{VC} \text {. }
$$

Perhitungan nilai $\mathrm{R} / \mathrm{C}$ usaha perikanan tangkap diperoleh melalui rumus :

$$
\mathrm{R} / \mathrm{C}=\frac{T R}{T C}
$$

Perhitungan nilai profitabilitas usaha perikanan tangkap diperoleh melalui rumus:

$$
\text { Profitabilitas }=\frac{T R}{T C} \frac{\pi}{\mathrm{TC}}
$$

Keterangan/ Information:

$$
\begin{aligned}
\pi= & \begin{array}{l}
\text { Keuntungan Usaha dalam Rupiah/ } \\
\text { Business profits in IDR }
\end{array} \\
\mathrm{TR}= & \begin{array}{l}
\text { Total Revenue (Total Penerimaan) } \\
\text { dalam Rupiah/ Total Revenue in IDR }
\end{array} \\
\mathrm{TC}= & \begin{array}{l}
\text { Total Cost (Total Biaya) dalam Rupiah/ } \\
\text { Total Cost in IDR }
\end{array} \\
\mathrm{FC=}= & \begin{array}{l}
\text { Fixed Costs (Biaya Tetap) dalam } \\
\text { Rupiah/ Fixed Costs in IDR }
\end{array} \\
\mathrm{VC}= & \text { Variable Costs (Biaya Variabel) dalam } \\
& \text { Rupiah/ Variable Costs in IDR }
\end{aligned}
$$

Terkait dengan prakiraan dampak penyesuaian harga BBM terhadap kondisi usaha, maka digunakan beberapa asumsiasumsi diantaranya adalah jumlah BBM, jumlah trip, kebutuhan armada BBM per tahun dan per

\begin{tabular}{|c|c|c|c|c|c|c|c|}
\hline \multirow{2}{*}{$\begin{array}{c}\text { Kategori Asumsi/ } \\
\text { Assumptions category }\end{array}$} & \multicolumn{7}{|c|}{ Ukuran Kapal (GT) / Vessel Size } \\
\hline & $<5$ & $5-10$ & $10-20$ & $20-30$ & $30-50$ & $50-100$ & $\begin{array}{l}100- \\
200\end{array}$ \\
\hline $\begin{array}{l}\text { Jumlah BBM / Volume of Fuels } \\
\text { (armada/trip) (primer) }\end{array}$ & 20 & 80 & 452 & 3,600 & 7,111 & 30,000 & 56,929 \\
\hline $\begin{array}{l}\text { Jumlah Trip (armada/tahun) / } \\
\text { Sum of Trip (armada/ year) }\end{array}$ & 216 & 36 & 20 & 18 & 9 & 4 & 3 \\
\hline $\begin{array}{l}\text { Kebutuhan BBM (armada / tahun)/ } \\
\text { Fuel Needs (armada/ year) }\end{array}$ & 4,320 & 2,880 & 9,040 & 64,800 & 64,000 & 120,000 & 170,786 \\
\hline $\begin{array}{l}\text { Kebutuhan BBM / Fuel Needs } \\
\text { (armada / bulan)/ (armada/month) }\end{array}$ & 360 & 240 & 753 & 5,400 & 5,333 & 10,000 & 14,232 \\
\hline $\begin{array}{l}\text { Kebutuhan BBM total (liter/tahun) } \\
\text { (dalam ribuan) / Total of Fuel } \\
\text { Needs (litre/year (in thousands) }\end{array}$ & 594,518 & 111,571 & 105,316 & 493,776 & 58,880 & 200,400 & 201,527 \\
\hline $\begin{array}{l}\% \text { kebutuhan BBM / terhadap } \\
\text { kebutuhan total / Percentage of } \\
\text { Fuel Needs to Total Needs }\end{array}$ & 34 & 6 & 6 & 28 & 3 & 11 & 11 \\
\hline
\end{tabular}
bulan. Selain itu, untuk kebutuhan perhitungan dampak terhadap kondisi usaha, digunakan empat penyesuaian harga BBM yaitu Rp. 5.500/liter, Rp. 6.400/liter, Rp. 7.500/liter dan Rp. 13.500/ liter. Harga pertama hingga ke tiga merupakan harga riil yang diumumkan oleh pemerintah, sedangkan harga ke empat merupakan harga maksimal yang memberikan dampak Break Even Point (BEP) terhadap ukuran kapal 50 - 100 GT.

Tabel 1. Asumsi-asumsi yang Digunakan untuk Perhitungan Prakiraan Dampak Penyesuaian Harga BBM terhadap Kondisi Usaha.

Table 1. The Assumptions Used for The Forecast Imapct Calculation of Fuel Price Adjustment to the Business Conditions. 


\section{HASIL DAN PEMBAHASAN}

\section{Biaya Investasi Pada Usaha Armada Perikanan Tangkap}

Dalam usaha penangkapan ikan, nelayan memiliki investasi pada kapal, mesin dan peralatan pendukung. Biaya investasi yang dibutuhkan makin besar sesuai dengan ukuran armada. Biaya investasi tertinggi dikeluarkan oleh kelompok armada > 100-200 GT yang mencapai 4,75 Milyar dan biaya investasi terendah dikeluarkan oleh armada < 5 GT sekitar 31,5 Juta. Kapal merupakan investasi yang sangat penting karena mencapai sekitar $70 \%$ dari total investasi. Mesin yang digunakan oleh kapal bervariasi dari yang fungsinya hanya sebagai pendorong kapal hingga yang berfungsi sebagai penarik jaring. Investasi mesin mencapai nilai hingga $20 \%$ dari total investasi. Alat tangkap yang digunakan mencapai sekitar $8 \%$ dari total investasi sedangkan sisanya digunakan untuk pembelian alat pendukung. Alat pendukung yang digunakan dalam perikanan tangkap laut seperti jaket pelampung, lampu, peralatan masak, dan GPS.

\section{Biaya Tetap dan Operasional Pada Usaha Armada Perikanan Tangkap}

Secara umum biaya yang dikeluarkan untuk melakukan usaha budidaya adalah biaya tetap (fixed cost) dan biaya variabel (variable cost). Biaya tetap merupakan biaya yang besarnya tidak akan dipengaruhi oleh tingkat operasi pada periode waktu tertentu (Supriyono, 2011). Biaya ini harus dikeluarkan sesuai dengan kebutuhan teknis meskipun tidak operasional (sedang tidak operasional). Biaya ini selalu dihubungkan dengan usia teknis sarana atau prasarana yang dipakai serta umur pakai yang berlaku lebih dari satu tahun penggunaannya. Adapun biaya tetap dalam kaitan dengan pemeliharaan kapal, sarana alat tangkap dan alat pendukung dalam aktivitas penangkapan. Biaya variabel merupakan biaya yang besarnya bervariasi mengikuti secara proporsional dengan jumlah produksi yang dihasilkan, biaya variabel akan nol/ tidak ada apabila produksinya nol atau tidak dilakukan kegiatan usaha penangkapan ikan.

Input produksi perikanan tangkap terdiri dari pembelian BBM : solar, bensin, oli, gas dan minyak tanah; pembelian air bersih, es, ransum, dan umpan. Pembelian BBM merupakan biaya operasional yang paling besar yang dikeluarkan oleh nelayan mencapai rata-rata sekitar $70 \%$ dari total biaya operasional. Jarak antara tempat pendaratan ikan atau landing based dengan fishing ground dan jarak antar fishing ground sangat mempengaruhi jumlah BBM yang dikonsumsi oleh setiap kapal per tripnya. Pembelian BBM oleh nelayan atau pemilik kapal dengan harga di atas harga normal menjadi beban tambahan dalam biaya operasional kapal. Selama ini, nelayan skala kecil terutama < 5 GT selama ini membeli BBM dengan harga di atas harga normal (harga SPBU). Mereka masih kesulitan dalam mengakses BBM dengan harga normal karena rata-rata jarak dari tempat pendaratan ikan ke SPBN, SPDN dan SPBU relatif jauh. Oleh karena itu, nelayan melakukan beberapa strategi dalam menekan biaya operasional. Ada beberapa pola nelayan dalam mendapatkan BBM dan menormalisasi biaya operasional, yaitu:

1. Mendaratkan ikan di tempat terdekat dengan fishing ground.

2. Menjual ikan secara langsung dengan pembeli yang menerima berbagai jenis ikan dengan berbagai kualitas.

3. Menjual ikan di tengah laut untuk mengurangi biaya-biaya untuk pelelangan, biaya tambat kapal.

Beberapa strategi di atas biasanya dilakukan oleh nelayan di beberapa wilayah perikanan di Indonesia terutama di Jawa. Hal tersebut terpaksa dilakukan nelayan karena untuk menjaga keberlanjutan usaha, mengingat mereka tidak bisa menghindar dari kenaikan harga BBM. Berdasarkan skala usaha perikanan tangkap, perahu < 5 GT merupakan kelompok kapal sebagai konsumen BBM terbesar dibandingkan dengan kelompok kapal yang lainnya. Sementara itu, kelompok kapal 20-30 GT, 30-50 GT dan 100-200 GT adalah kelompok yang mengkonsumsi BBM paling kecil. Hasil ini mempertimbangkan jumlah trip per tahun dan jumlah total kebutuhan BBM pada masing-masing kelompok kapal. Berdasarkan jumlah perahu, kelompok perahu > 300 GT adalah konsumen BBM terbesar mengingat jumlah kapalnya sedikit dibandingkan kelompok kapal < 5 GT. Biaya tetap paling besar dikeluarkan oleh kelompok armada 100-200 GT yang mencapai sekitar 430 juta per tahun dan yang paling kecil adalah kelompok armada $<5$ GT yakni sebesar 8,7 juta per tahun. Biaya variabel berubah karena terjadi kenaikan harga BBM solar. Sebelum bulan November 2014 harga BBM solar adalah Rp 5.500/liter, kemudian setelah bulan November naik menjadi Rp 7.500,-/ liter dan kemudian pada bulan Januari turun kembali menjadi Rp 6.400,-/liter. Biaya tidak tetap 
paling besar ada pada kelompok armada 100-200 GT yakni mencapai Rp 1,078 - Rp 1,42 Milyar/ tahun dan paling kecil ada pada armada < 5 GT yakni sebesar Rp 40 - Rp 48 Juta/tahun.

\section{Penerimaan dan Keuntungan Usaha}

Secara umum, penerimaan usaha dari beberapa kelompok armada paling besar ada pada kelompok 100-200 GT yakni sebesar 3,5 Milyar/ tahun dan yang paling kecil ada pada kelompok $<5$ GT yaitu sebesar 97 Juta/tahun. Keuntungan yang diterima oleh nelayan pada kelompok 100-200 GT sebesar 2,058 Milyar/tahun dan kelompok < 5 GT sebesar 49 juta/tahun. R/C dari kelompok 20-30 GT paling besar diantara kelompok armada lainnya yaitu sebesar 2,93 hingga 3,40 dan yang paling kecil ada pada kelompok armada ukuran 5-10 GT yakni sebesar 1,31 sampai 1,42.

\section{Prakiraan Dampak Penyesuaian Harga BBM terhadap Kondisi Usaha}

Penyesuaian harga BBM khususnya solar yang terjadi pada akhir tahun 2014 hingga Januari 2015 memberi dampak kepada sektor kelautan dan perikanan karena BBM merupakan input yang paling dominan dalam mendukung usaha penangkapan. Berdasarkan hasil analisis diperoleh informasi bahwa kapal berukuran 50 - 100 GT adalah kelompok yang paling sensitif terkena dampak akibat perubahan harga solar dari Rp 5.500,- ke Rp 7.500,- (harga BBM naik 36\%) keuntungan menurun sebesar $25 \%$ dan ketika harga solar menjadi Rp 6.400,-- (harga BBM turun
$15 \%)$, keuntungan naik sebesar $18 \%$. Sedangkan kapal berukuran 20 - 30 GT adalah kelompok yang memiliki dampak paling kecil terhadap perubahan harga. Harga BBM naik $36 \%$ menyebabkan keuntungan menurun sebesar $7 \%$ dan harga BBM turun sebesar $15 \%$ menyebabkan keuntungan naik sebesar 4\%. Jika harga solar dinaikkan hingga menjadi Rp 13.500,- dan harga ikan diasumsikan tetap maka kelompok kapal 50-100 GT berada pada kondisi Break Even Point (titik impas) dimana $\mathrm{R} / \mathrm{C}=1$. Kenaikan harga BBM tanpa disertai oleh kenaikan harga ikan dipastikan menyebabkan kerugian bagi nelayan di setiap ukuran armada. Sehingga perlu ada kebijakan-kebijakan yang tepat dapat mengatasi permasalahan tersebut seperti perbaikan infrastruktur kelautan dan perikanan pada seluruh pelabuhan perikanan dan perbaikan sistem distribusi ikan untuk menjaga kestabilan harga ikan.

Tabel prakiraan dampak penyesuaian harga BBM dapat dilihat pada Tabel 2 hingga Tabel 5 . Pada Tabel 2 digunakan asumsi harga solar Rp 5.500,- per liter dan tidak adanya perubahan harga ikan hasil tangkapan nelayan. Harga solar tersebut, merupakan harga awal/normal sebelum adanya perubahan harga BBM. Berdasarkan harga BBM tersebut, maka nilai R/C rata-rata masih di atas 1 sehingga usaha masih bisa dianggap layak. R/C terbesar pada ukuran kapal 20-30 GT sebesar 3,40 dan yang paling kecil ada pada ukuran 5-10 GT yaitu sebesar 1,42. Secara lebih lengkap, simulasi dampak penyesuaian harga terhadap kondisi usaha dapat dilihat pada Tabel 2.

Tabel. 2 Simulasi Dampak Penyesuaian Harga BBM Solar Terhadap Kondisi Usaha dengan Harga Rp. 5.500/ Liter.

Table 2. Simulation Impact of Solar Fuel Price Adjustment to Business Conditions With Price Rp. 5.500/ Liter.

\begin{tabular}{|c|c|c|c|c|c|c|c|}
\hline \multirow{2}{*}{$\begin{array}{c}\text { Komponen/ } \\
\text { Component } \\
\text { (Rp. 000) }\end{array}$} & \multicolumn{7}{|c|}{ Ukuran Kapal/Size Boat } \\
\hline & $<5 \mathrm{GT}$ & $5-10 \mathrm{GT}$ & $10-20 \mathrm{GT}$ & $20-30 \mathrm{GT}$ & $30-50 \mathrm{GT}$ & $50-100 \mathrm{GT}$ & $100-200 \mathrm{GT}$ \\
\hline $\begin{array}{l}\text { Biaya Investasi/ } \\
\text { Investment Cost }\end{array}$ & 31,512 & 123,900 & 355,000 & 760,000 & 657,565 & $1,402,000$ & $4,750,000$ \\
\hline $\begin{array}{l}\text { Biaya Tidak Tetap/ } \\
\text { Unfixed Cost }\end{array}$ & 39,594 & 42,005 & 108,958 & 581,584 & 630,492 & 799,114 & $1,078,997$ \\
\hline $\begin{array}{l}\text { Biaya Tetap/ } \\
\text { Fixed Cost }\end{array}$ & 8,721 & 26,520 & 80,675 & 219,675 & 164,375 & 348,150 & 429,875 \\
\hline $\begin{array}{l}\text { Total Biaya/ } \\
\text { Total Cost }\end{array}$ & 48,316 & 68,525 & 189,633 & 801,259 & 794,867 & $1,147,264$ & $1,508,872$ \\
\hline Penerimaan/Income & 97,200 & 97,200 & 367,000 & $2,727,000$ & $2,055,000$ & $2,110,000$ & $3,567,857$ \\
\hline Keuntungan/Profit & 48,884 & 28,675 & 177,367 & $1,925,741$ & $1,260,133$ & 962,736 & $2,058,985$ \\
\hline R/C Ratio & 2.01 & 1.42 & 1.94 & 3.40 & 2.59 & 1.84 & 2.36 \\
\hline
\end{tabular}

Keterangan: Asumsi Harga Ikan Tetap, Produksi Perikanan Tetap, dan Kebutuhan BBM/trip tetap/

Description: Assumption Fish Fixed Price, Fixed Fisheries Production and Supplies of fuel / Regular Trip 
Simulasi kedua adalah menggunakan harga BBM sebesar Rp. 6.400 (kenaikan sebesar 16\% dari harga BBM eksisting). Kondisi kenaikan harga BBM tersebut, secara umum memberikan dampak yang besar terhadap keuntungan usaha yang mana keuntungan usaha mengalami penurunan pada seluruh ukuran kapal. Pada akhirnya, penurunan keuntungan usaha akan mempengaruhi juga R/C. Nilai R/C pada harga BBM Rp. 6.400 terendah maupun tertinggi sama dengan nilai $\mathrm{R} / \mathrm{C}$ pada harga BBM Rp. 5.500 yaitu pada ukuran kapal 5 - 10 GT dan 20 - 30 GT (Tabel 3).

Simulasi ketiga adalah menggunakan harga BBM Rp. 7.500 (kenaikan sebesar Rp. 17\% dari harga Rp. 6.400). Kondisi tersebut semakin memberikan tekanan yang lebih besar kepada keuntungan usaha perikanan. Menurut nilai R/C, nilai terendah maupun tertinggi juga tidak banyak perubahan yaitu pada ukuran kapal 5 - 10 GT dan ukuran 20 - 30 GT (Tabel 4).
Pada simulasi keempat, harga BBM diasumsikan naik mencapai Rp. 13.500 per liter. Alasan dari penggunaan harga tersebut karena nilai ini merupakan titik impas / Break Even Point (BEP) pada ukuran kapal 50 - 100 GT. Dengan kata lain, harga BBM tersebut merupakan harga maksimal kondisi usaha pada berbagai ukuran kapal dapat berjalan. Harga BBM yang melebihi nilai tersebut, dapat dipastikan usaha perikanan tidak dapat berjalan dan dapat menimbulkan gejolak pada pelaku usaha perikanan. Namun, perlu diperjelas kembali bahwa hasil analisis tersebut menggunakan beberapa asumsi diantaranya adalah (1) harga ikan tetap, (2) volume ikan hasil tangkapan tetap, dan (3) kebutuhan BBM per trip tetap. Dengan kata lain, hasil analisis ini terdapat kelemahan karena tidak memperhitungkan perubahan dinamika harga ikan, produksi maupun kebutuhan BBM (Tabel 5).

Tabel 3. Simulasi Dampak Penyesuaian Harga BBM Solar Terhadap Usaha dengan Harga Rp 6.400,-/liter.

Table 3. Simulation Impact of Solar Fuel Price Adjustment to Business Conditions With Price Rp.6.400, - / Liter.

\begin{tabular}{lrrrrrrr}
\hline \multirow{2}{*}{$\begin{array}{c}\text { Komponen/Component } \\
\text { (Rp. 000) }\end{array}$} & \multicolumn{7}{c}{ Kapal Menurut Ukuran/ Size Boat } \\
\cline { 2 - 8 } & $\mathbf{<} \mathbf{5 ~ G T}$ & $\mathbf{5 - 1 0 ~ G T}$ & $\mathbf{1 0 - 2 0 ~ G T}$ & $\mathbf{2 0 - 3 0 ~ G T}$ & $\mathbf{3 0 - 5 0 ~ G T}$ & $\mathbf{5 0 - 1 0 0 ~ G T ~}$ & $\mathbf{1 0 0 - 2 0 0 ~ G T}$ \\
\hline Biaya Investasi / Investment Cost & 31,512 & 123,900 & 355,000 & 760,000 & 657,565 & $1,402,000$ & $4,750,000$ \\
Biaya Tidak Tetap / Unfixed Cost & 43,482 & 44,597 & 117,094 & 639,904 & 701,394 & 907,114 & $1,232,704$ \\
Biaya Tetap / Fixed Cost & 8,721 & 26,520 & 80,675 & 219,675 & 164,375 & 348,150 & 429,875 \\
Total Biaya / Total Cost & 52,204 & 71,117 & 197,769 & 859,579 & 865,769 & $1,255,264$ & $1,662,579$ \\
Penerimaan / Income & 97,200 & 97,200 & 367,000 & $2,727,000$ & $2,055,000$ & $2,110,000$ & 3,568 \\
Keuntungan / Profit & 44,996 & 26,083 & 169,231 & 1,867 & 1,189 & 855 & 1,905 \\
R/C Ratio & 1.86 & 1.37 & 1.86 & 3.17 & 2.37 & 1.68 & 2.15 \\
\hline
\end{tabular}

Keterangan: Asumsi Harga Ikan Tetap, Produksi Perikanan Tetap, dan Kebutuhan BBM/trip tetap/

Description: Assumption Fish Fixed Price, Fixed Fisheries Production and Supplies of Fuel / Regular Trip

Tabel 4. Simulasi Dampak Penyesuaian Harga BBM Solar Terhadap Usaha dengan Harga Rp 7.500,-/liter.

Table 4. Simulation Impact of Solar Fuel Price Adjustment to Business Conditions With Price Rp.7.500, - / Liter.

\begin{tabular}{|c|c|c|c|c|c|c|c|}
\hline \multirow{2}{*}{$\begin{array}{c}\text { Komponen/ Component } \\
(\text { Rp. 000) }\end{array}$} & \multicolumn{7}{|c|}{ Kapal Menurut Ukuran/ Size boat } \\
\hline & $<5$ GT & 5-10 GT & $10-20 \mathrm{GT}$ & $20-30 \mathrm{GT}$ & $30-50 \mathrm{GT}$ & $50-100 \mathrm{GT}$ & $100-200 \mathrm{GT}$ \\
\hline Biaya Investasi / Investment Cost & 31,512 & 123,900 & 355,000 & 760,000 & 657,565 & $1,402,000$ & $4,750,000$ \\
\hline Biaya Tidak Tetap / Unfixed Cost & 48,235 & 47,765 & 127,038 & 711,184 & 788,052 & $1,039,114$ & $1,420,569$ \\
\hline Biaya Tetap / Fixed Cost & 8,721 & 26,520 & 80,675 & 219,675 & 164,375 & 348,150 & 429,875 \\
\hline Total Biaya / Total Cost & 56,956 & 74,285 & 207,713 & 930,859 & 952,427 & $1,387,264$ & $1,850,444$ \\
\hline Penerimaan / Income & 97,200 & 97,200 & 367,000 & $2,727,000$ & $2,055,000$ & $2,110,000$ & $3,567,857$ \\
\hline Keuntungan / Profit & 40,244 & 22,915 & 159,287 & $1,796,141$ & $1,102,573$ & 722,736 & $1,717,413$ \\
\hline R/C Ratio & 1.71 & 1.31 & 1.77 & 2.93 & 2.16 & 1.52 & 1.93 \\
\hline
\end{tabular}

Keterangan: Asumsi Harga Ikan Tetap, Produksi Perikanan Tetap, dan Kebutuhan BBM/trip tetap/

Description: Assumption Fish Fixed Price, Fixed Fisheries Production and Supplies of Fuel / Regular Trip 
Tabel 5. Simulasi Dampak Penyesuaian Harga BBM Solar terhadap usaha dengan harga Rp 13.500,-/liter.

Table 5. Simulation Impact of Solar Fuel Price Adjustment to Business Conditions With Price Rp.13.500, - / Liter.

\begin{tabular}{lrrrrrrr}
\hline \multirow{2}{*}{$\begin{array}{c}\text { Komponen/ Component } \\
\text { (Rp. 000) }\end{array}$} & \multicolumn{7}{c}{ Kapal menurut ukuran/ Size boat } \\
\cline { 2 - 8 } & \multicolumn{1}{c}{$\mathbf{5 ~ G T}$} & $\mathbf{5 - 1 0 ~ G T}$ & $\mathbf{1 0 - 2 0 ~ G T}$ & $\mathbf{2 0 - 3 0}$ GT & $\mathbf{3 0 - 5 0 ~ G T}$ & $\mathbf{5 0 - 1 0 0 ~ G T ~}$ & $\mathbf{1 0 0 - 2 0 0 ~ G T ~}$ \\
\hline Biaya Investasi / Investment Cost & 31,512 & 123,900 & 355,000 & 760,000 & 657,565 & $1,402,000$ & $4,750,000$ \\
Biaya Tidak Tetap / Unfixed Cost & 69,835 & 63,605 & 176,758 & $1,067,584$ & $1,260,732$ & $1,759,114$ & $2,445,283$ \\
Biaya Tetap / Fixed Cost & 8,721 & 26,520 & 80,675 & 219,675 & 164,375 & $348,150,000$ & 429,875 \\
Total Biaya / Total Cost & 78,556 & 90,125 & 257,433 & $1,287,259$ & $1,425,107$ & $2,107,264$ & $2,875,158$ \\
Penerimaan / Income & 97,200 & 97,200 & 367,000 & $2,727,000$ & $2,055,000$ & $2,110,000$ & $3,567,857$ \\
Keuntungan / Profit & 18,644 & 7,075 & 109,567 & $1,439,741$ & 629,893 & 2,736 & 692,699 \\
R/C Ratio & 1.24 & 1.08 & 1.43 & 2.12 & 1.44 & 1.00 & 1.24 \\
\hline
\end{tabular}

Keterangan: Asumsi Harga Ikan Tetap, Produksi Perikanan Tetap, dan Kebutuhan BBM/trip tetap/

Description: Assumption Fish Fixed Price, Fixed Fisheries Production and Supplies of Fuel / Regular Trip

Gambar 2 menunjukkan rangkuman perbandingan nilai $\mathrm{R} / \mathrm{C}$ terhadap empat penyesuaian harga pada berbagai ukuran kapal. Terlihat bahwa pada seluruh ukuran kapal, perubahan harga BBM sangat mempengaruhi nilai $\mathrm{R} / \mathrm{C}$. Penurunan pada masing-masing ukuran kapal terlihat sangat statis (tidak dinamis) karena telah dijelaskan sebelumnya bahwa hanya harga BBM yang mengalami perubahan. Berdasarkan Gambar 2 tersebut, dapat dijelaskan bahwa terdapat dua kelompok ukuran kapal yang memiliki perbedaan kerentanan terhadap kenaikan harga BBM. Kelompok pertama terdiri dari ukuran kapal < $5 \mathrm{GT}$, 5 - 10 GT, 10 - 20 GT dan 50 - 100 GT. Kelompok ini dapat dikategorikan kerentanan tinggi terhadap perubahan harga BBM karena nilai R/C kurang dari 2. Sedangkan kelompok kedua terdiri dari ukuran kapal 20 - 30 GT, 30 - 50 GT dan lebih dari 100 GT yang memiliki kerentanan rendah karena nilai $R / C$ lebih dari 2. Hal ini menunjukkan bahwa kelompok 1 yang didominasi oleh perikanan skala kecil kondisi usahanya yang lebih rentan terhadap perubahan harga BBM dibandingkan dengan kelompok 2 yang didominasi oleh perikanan skala besar.

\section{KESIMPULAN DAN IMPLIKASI KEBIJAKAN}

\section{Kesimpulan}

Beberapa kesimpulan yang dapat ditarik dari hasil penelitian ini adalah :

Penyesuaian harga BBM memiliki pengaruh yang sangat besar terhadap biaya operasional dan keuntungan usaha. Pada seluruh ukuran kapal peningkatan harga BBM akan secara otomatis meningkatkan biaya operasional usaha dan menurunkan keuntungan usaha.

Terdapat dua kelompok ukuran kapal yang memiliki perbedaan kerentanan terhadap kenaikan harga BBM. Kelompok pertama terdiri dari ukuran kapal < 5 GT, 5 - 10 GT, 10 - 20 GT dan 50 - 100

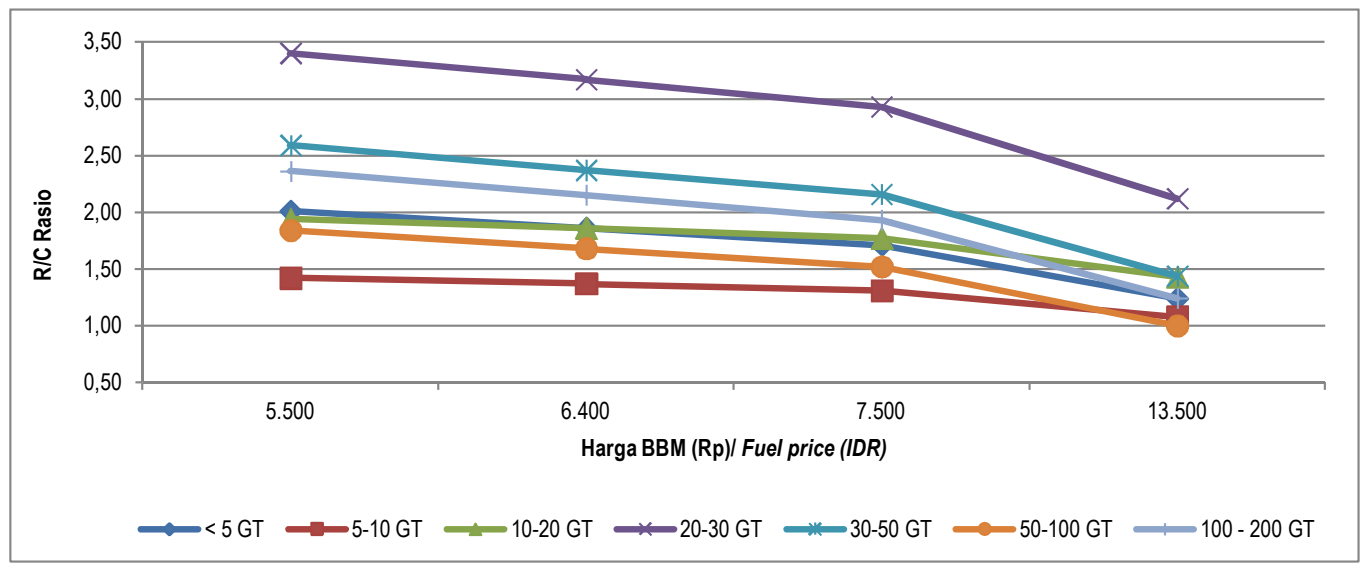

Gambar 2. Nilai R/C Berdasarkan Empat Penyesuaian Harga BBM pada Berbagai Ukuran Kapal Figure 2. Value of R/C Based on the Four Fuel Price Adjustment on Various Sizes of Vessels 
GT. Kelompok ini dapat dikategorikan kerentanan tinggi terhadap perubahan harga BBM karena nilai $\mathrm{R} / \mathrm{C}$ kurang dari 2. Sedangkan kelompok kedua terdiri dari ukuran kapal 20 - 30 GT, 30 - 50 GT dan lebih dari 100 GT yang memiliki kerentanan rendah karena nilai R/C lebih dari 2.

Kelompok 1 yang didominasi oleh perikanan skala kecil kondisi usahanya memang lebih rentan terhadap perubahan harga BBM dibandingkan dengan kelompok 2 yang didominasi oleh perikanan skala besar.

\section{Implikasi Kebijakan}

Implikasi kebijakan yang dirumuskan berdasarkan hasil penelitian ini adalah sebagai berikut:

Kebutuhan BBM untuk sektor perikanan sebesar 1,86 juta kilo liter/tahun dengan proporsi terbesar pada ukuran $\leq 5$ GT yakni $32 \%$ dari total kebutuhan BBM dan ukuran kapal > 20 - 30 GT sebesar $27 \%$.

Kapal berukuran $>30-50$ GT adalah kelompok yang paling terkena dampak akibat kenaikan biaya operasional yaitu sebesar $52 \%$, kemudian s 5 GT (39\%), 50 - 100 GT (35\%) dan 5 - 10 GT (19\%). Sementara itu, penurunan keuntungan paling besar diperkirakan akan dialami oleh kapal berukuran 30 - 50 GT (142\%), terutama pada kondisi harga ikan normal (tidak mengalami kenaikan).

Kompensasi dapat diberikan kepada kelompok $\leq 5$ GT sebesar 0,6 Triliun, 1,2 Triliun atau 1,3 Triliun sesuai dengan asumsi kenaikan harga BBM per liternya masing-masing $\mathrm{Rp}$. 1.000,-/liter, Rp. 2.000,-/liter dan Rp. 3.000,-/liter. Kompensasi untuk kelompok kapal $\leq 5$ GT dapat diberikan bantuan langsung, atau membangun infrastruktur jaminan harga ikan. Sementara itu, pengalihan subsidi untuk kapal 50 GT - 200 GT dapat digunakan untuk perbaikan, pengadaan dan pemeliharaan infrastruktur kelautan dan perikanan dalam rangka mendorong operasi kapal penangkapan ke wilayah Zona Ekonomi Eksklusif (200 mil laut).

Perubahan harga BBM khususnya solar yang terjadi pada akhir tahun 2014 hingga Januari 2015 memberikan dampak positif dan negatif terhadap pelaku usaha, khususnya nelayan; penurunan harga BBM berpotensi menaikkan tingkat keuntungan yang diterima, sebaliknya peningkatan BBM berpotensi menurunkan tingkat keuntungan usaha.

Perlu adanya bantuan permodalan dan pendampingan yang mendorong pelaku usaha berpindah dari kapal 50 - 100 GT ke kapal berukuran 20-30 GT atau ke kapal berukuran lebih dari 100 GT. Hal ini didasarkan pada hasil kajian dimana kelompok ukuran kapal 50 - 100 GT yang paling sensitif terkena dampak akibat perubahan harga solar. Setiap kenaikan harga BBM solar sebesar $1 \%$ akan menurunkan keuntungan usaha sebesar 0,7\%. Sementara ukuran kapal 20 - 30 GT dan lebih dari 100 GT mengalami penurunan sebesar $0,2 \%$ dan $0,5 \%$.

\section{UCAPAN TERIMA KASIH}

Penulis mengucapkan terima kasih kepada Kepala Pusat Penelitian Sosial Ekonomi Kelautan dan Perikanan yang telah mendukung sepenuhnya kegiatan Analisis Kebijakan Dampak Penyesuaian Harga BBM Bersubsidi Untuk Nelayan pada tahun 2015. Terima kasih penulis juga kepada pihakpihak lainnya yang telah membantu kegiatan ini sampai menghasilkan karya tulis ilmiah sehingga dapat memberikan sumbangsih bagi pengambil kebijakan terkait penyesuaian harga BBM.

\section{DAFTAR PUSTAKA}

Alamsyah, I. E. 2014. Penjualan BBM llegal Libatkan Kapal Asing. http://www.republika.co.id/berita/ nasional/umum/14/09/04/nbdhk8-penjualan-bbm-ilegal-libatkan-kapal-asing. Diakses 4 September 2014.

Anonim. 2014. Bank Dunia Dukung Subsidi BBM Tetap. http://www.tempo.co/read/ news/2014/04/07/092568561/Bank-Dunia-Dukung-Subsidi-BBM-Tetap. Di akses 9 April 2014.

Handoko, R. dan P. Patriadi. 2005. Evaluasi Kebijakan Subsidi Non BBM. Kajian Ekonomi dan Keuangan. Vol 9 No. 4. Jakarta

Harianto. 2003. Kajian Kelayakan Usaha Ekspor Ikan Kerapu Dengan Penerapan Alat Pengangkutan Darat Dan Teknik Kemasan Pengiriman Udara. Jurnal Sains dan Teknologi Indonesia, Vol. 5, No. 5, hal: 180-183.

Kinseng, R. A. 2007. Konflik-Konflik Sumberdaya Alam di Kalangan Nelayan di Indonesia. SODALITY; Jurnal Transdisiplin Sosiologi, Komunikasi dan Ekologi Manusia Vol 1 tahun 2007. Institut Pertanian Bogor. 
Maharani, E. 2014. Cara Susi Bujuk Nelayan Dukung Kebijakan BBM. http://nasional.republika.co.id/ berita/nasional/umum/14/11/11/nedyy0-cara-susi-bujuk-nelayan-dukung-kebijakan-bbm. Diakses 9 April 2014.

Nugroho, H. 2005. Apakah Persoalannya pada Subsidi BBM?Tinjauan terhadap Masalah Subsidi BBM, Ketergantungan pada Minyak Bumi, Manajemen Energi Nasional, dan Pembangunan Infrastruktur Energi. Majalah Perencanaan Pembangunan, 10(2): 2-18.

Saleh, M. H. 2013. KEBIJAKAN PEMERINTAHAN SBY-JK TENTANG KENAIKAN HARGA BBM 1 Oktober 2005. Jurnal Sosial Politik Vol. 6 No. 12. Universitas Mulawarman. Samarinda
Sukirno, S. 2005. Makro Ekonomi Teori Pengantar.Raja Grafindo Perkasa.Jakarta.

Supriyono, R. 2011. Akuntansi Biaya, Perencanaan dan Pengendalian Biaya, Serta Pengambilan Keputusan. Badan Penerbitan Fakultas Ekonomika dan Bisnis (BPFE). Yogyakarta

Todaro, M. P. and S. C. Smith. 2009.Economic Development (ed. 10th). Addison Wesley.

Yusgiantoro, P. 2000. Ekonomi Energi, Teori dan Praktik. Pustaka Lembaga Penelitian, Pengkajian, dan Pengembangan Ekonomi dan Sosial, Jakarta. 